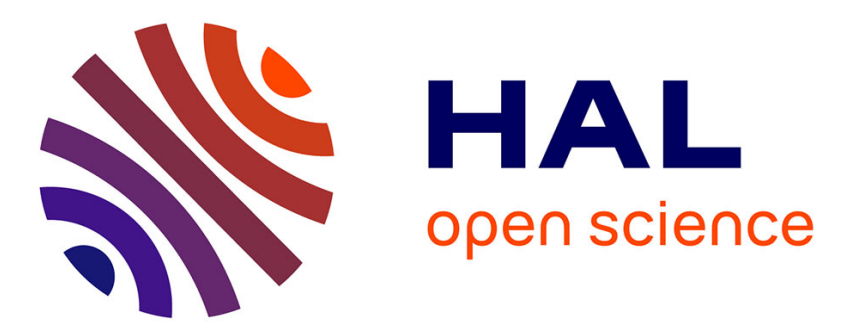

\title{
Assessment of free-edge singularities in composite laminates using higher-order plate elements
}

\author{
C. Wenzel, M. d'Ottavio, O. Polit, P. Vidal
}

\section{To cite this version:}

C. Wenzel, M. d'Ottavio, O. Polit, P. Vidal. Assessment of free-edge singularities in composite laminates using higher-order plate elements. Mechanics of Advanced Materials and Structures, 2016, Applications of Unified Formulation and advanced theories using several numerical approaches, 23 (9), pp.948-959. 10.1080/15376494.2015.1121526 . hal-01367030

\section{HAL Id: hal-01367030 \\ https://hal.science/hal-01367030}

Submitted on 8 Jan 2018

HAL is a multi-disciplinary open access archive for the deposit and dissemination of scientific research documents, whether they are published or not. The documents may come from teaching and research institutions in France or abroad, or from public or private research centers.
L'archive ouverte pluridisciplinaire HAL, est destinée au dépôt et à la diffusion de documents scientifiques de niveau recherche, publiés ou non, émanant des établissements d'enseignement et de recherche français ou étrangers, des laboratoires publics ou privés. 


\title{
ACCEPTED MANUSCRIPT
}

\section{Assessment of free-edge singularities in composite laminates using higher-order plate elements}

\author{
C. Wenzel M. D’Ottavio* $\quad$ O. Polit P. Vidal \\ Laboratoire Energétique Mécanique Electromagnétisme - EA4416 \\ Université Paris Ouest - Nanterre - La Défense \\ 50, rue de Sèvres, 92410 Ville d'Avray, France
}

\begin{abstract}
The capabilities and limitations of refined two-dimensional (2D) composite plate elements are discussed with respect to the stress concentration problem occurring at traction-free edges. Classical displacement-based and advanced partially mixed finite elements are formulated according to Carrera's Unified Formulation (CUF). Rectangular laminates are analyzed under extension and bending loading, where the attention is focused on the local stress response at the free edges. Present results are compared with reference results available in literature and a 3D finite element model. A power law representation for a singular stress field is used to fit the obtained stresses in vicinity of the free edge and the parameters are used to assess the CUF elements and to compare the free-edge effect occurring in extension and bending.
\end{abstract}

Keywords: Carrera Unified Formulation, refined plate element, free-edge effect, stress singularities, power law

${ }^{*}$ Corresponding author. Email: mdottavi@u-paris10.fr 


\section{ACCEPTED MANUSCRIPT}

\section{Introduction}

Fibre-reinforced composite laminates are being increasingly used in advanced structural applications, due to their excellent specific stiffness and strength properties. By stacking several composite plies with different orientations of the fibrous reinforcement, stiffness and strength can be tailored to meet the specific loading conditions of the panel. Their heterogenous composition and anisotropic nature demands appropriate numerical tools to reliably predict the behavior of these structures. A huge amount of scientific effort is being accordingly developed, which tries to cope with the difficulties related to the heterogeneous microscale (fiber and matrix level) and its homogenization suitable for the structural scale.

A well accepted homogenization scheme represents the composite laminate as a stack of homogeneous, anisotropic plies that are separated by bi-material interfaces (Effective Modulus Theory) [1]. Based on this representation, a large number of beam, plate and shell formulations have been developed in order to enhance the stress prediction inside the laminates within computationally efficient structural models [2]. In the so-called Equivalent Single Layer (ESL) models, to which belong the well known Classical Laminate Theory (CLT) and First-order Shear Deformation Theory (FSDT), the number of unknown parameters is independent of the number of layers constituting the stack. High-order Shear Deformation Theories (HSDT) enhance the transverse shear behavior of ESL models [3]. However, these models cannot represent the response at bi-material interfaces where, according to EMT, the transverse stresses need to be continuous (interlaminar equilibrium) and the displacement field has consequently a discontinuous slope along the thickness direction. So-called Zig-Zag Theories (ZZT) can represent up to a certain extent these interfaces still within an ESL approach [4]. Within the Effective Modulus Theory, the most refined description considers each ply's properties separately; in these Layer-Wise (LW) models, the number of unknown parameters depends on the number of the represented layers.

Most dimensionally reduced models are based on the plane stress assumption and refer there-

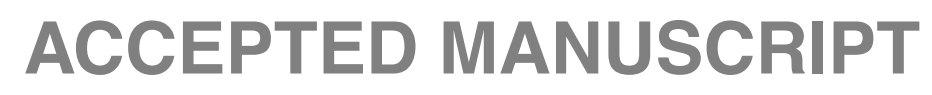




\section{ACCEPTED MANUSCRIPT}

fore to the 2D constitutive law. A discriminant feature of these reduced models consists in their capability of capturing the transverse stress components [5]. These interlaminar stresses act at the bi-material interfaces and are the most critical ones since they are responsible for promoting delamination failure. Since transverse stresses are inherently 3D, various methods have been proposed in order to reliably predict them starting from the reduced computational models, see, e.g., [6]: integration of the 3D equilibrium equations to post-process the in-plane stress field [7], or a global-local sub-modeling technique with appropriate schemes to connect adjacent subregions employing differently refined models [8-10].

From the above discussion, it appears interesting to assess different models with respect to their capacity to capture transverse stress concentrations. Among the configurations with transverse stress concentrations, the free-edge effect occurring at traction-free edges of loaded laminates is the one that received most attention. Bi-material discontinuity at the free edge introduces very high stress gradients which may even show a singular behavior [11]. Since the seminal work of Pipes and Pagano [12], many studies focussed on the free-edge effect arising in symmetric laminates subjected to a longitudinal strain (extension load). In this so-called Pipes-Pagano problem, several simplifications can be exploited to reduce the computational problem and hence concentrate the effort on the resolution of the highly localized free-edge stress gradients: besides evident symmetry conditions, de Saint Venant's principle can be invoked to formulate a quasi-3D (Q3D) model, which reduces the computational domain to the central cross-section of the laminate. This way, the solution of free-edge problems was accessible to the limited computing power of the time: first results have been obtained by Pipes and Pagano [12] within a Finite Difference (FD) scheme and early Finite Element (FE) solutions have been proposed, among others, by Wang and Crossman [13] and Raju and Crews Jr [14]. This latter paper discussed the existence of a singular stress field at the free edge and proposed a power-law $r^{-\alpha}$ representation of the singularity. Wang and Stango [15] proposed an optimized FE mesh for the computation of free-edge stresses with particular attention to the extrapolation of the stress components at the bi-material interface, 


\section{ACCEPTED MANUSCRIPT}

where displacement-based methods fail to satisfy the transverse stress continuity required by the equilibrium condition. Mixed-hybrid FE methods have been thus proposed to enhance the interlaminar stresses $[16,17]$. It is interesting to note that these works yield contradictory conclusions with regard to the stress singularity, in particular Spilker and Chou [16] rejected the presence of singularities.

Ghiringhelli and Sala [18] applied the FE analysis of the stress singularity to a laminate model that included a resin-rich interlaminar layer, which lead to a weaker singularity with respect to models with bare bi-material interfaces. Ye [19] assessed the effect of material nonlinearities in the free-edge response and concluded that a linear elastic analysis is sufficiently accurate for the analysis of inter laminar stresses. In this paper, the Q3D-based FE analyses addressed laminates subjected to longitudinal extension as well as pure bending in the $x z$ plane. Bar-Yoseph and BenDavid [20] applied the mixed-hybrid FE of [17] for comparing free-edge effects originated by bending and extension loads and concluded that the edge effects are stronger for the extension case. It is interesting to note that the opposite conclusion was drawn by Murthy and Chamis [21] by means of a classical 3D displacement-based FE method that included, however, the resin-rich interlaminar layer.

Alternative, not FE-based approaches to the Pipes-Pagano problems have been developed on the basis of the Q3D model: the semi-analytic method of Wang and Choi, based on Lekhnitskii's complex stress functions, demonstrated that the transverse stresses at the free edge are weakly singular [22] and permitted to present an elasticity solution for the free-edge stress fields [23]. Kassapoglou and Lagace [24] proposed an efficient stress-based solution through the minimization of the complementary energy, which has been later extended to unsymmetric laminates and combined loading by Kassapoglou [25]. Davì and Milazzo [26] conveniently applied the Boundary Element Method (BEM) to compute the stress field and its singularity at the free edge.

While most findings concerning the free-edge problem have been realized within the Q3D model, several authors analyzed the free-edge problems by means of more general plate models, 


\section{ACCEPTED MANUSCRIPT}

where the computational domain is not limited to a cross-section but represents the whole laminate. A global-local modeling technique based on kinematic refinement of plate elements has been proposed by Robbins Jr and Reddy [8]: simple ESL plate elements have been used to globally mesh the plate, and a local mesh consisting of refined LW plate elements is superposed to it in the boundary layer. A partially mixed plate element has been developed and successfully applied to the free-edge problem by Ramtekkar and Desai [27]. Nguyen and Caron [28] applied a previously developed refined plate model inspired by Pagano [29] to the free-edge problem. A layer-wise mesh refinement along the laminate thickness has been subsequently proposed for this model by Saeedi et al. [30] in order to enhance the representation of the stress singularities. Semi-analytical solutions for free-edge effects have been developed as well: Tahani and Nosier [31] studied general cross-ply laminates subjected to bending loads on the basis of Lévy's approach and using the LW description developed by Robbins Jr and Reddy [32] and already employed in [8]. On the basis of de Saint Venant's principle for long plates, the full 3D problem can be split into a global plate problem defined in the mid-plane of the plate and a local Q3D problem defined in the cross-section. This approach has been applied to analyze free-edge effects occurring in general laminates subjected to various loading (extension, bending, torsion), where FSDT is used for the plate problem and the LW model for the local Q3D problem [33-36].

In a preceding paper [37], several plate models formulated according to the established Carrera's Unified Formulation (CUF) [38] have been assessed with respect to the stress fields predicted at free edges of laminates subjected to extensional loading only. In this paper, FE results obtained by CUF plate elements are used to identify the parameters of the power-law stress singularity, which will in turn be employed to assess the models and to compare the edge effect due to bending and extension. The paper is organized as follows. The various plate models and their FE implementation are presented in Section 2 along with the systematic description of the case studies and the employed meshes. In Section 3, the most accurate plate models are validated against literature results by comparing the stress fields and Section 4 presents the approach for identifying the stress

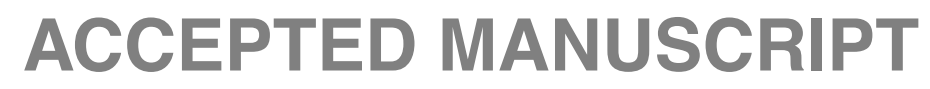




\section{ACCEPTED MANUSCRIPT}

singularity. The comparison between different models and between the extension and bending loading is carried out in Section 5. Conclusions are finally drawn in Section 6.

\section{Modelling approach}

\subsection{Description of the multilayered plate}

The rectangular laminated plate has a length of $2 a$ along the longitudinal $x$ direction, a width $2 b$ along $y$ and a thickness $h$ along $z$. The in-plane axes $x, y$ identify the plate's mid-surface, so that $z \in\left[-\frac{h}{2}, \frac{h}{2}\right]$, see Fig. 1(a). The laminate consists of $k=1,2, \ldots, N_{l}$ plies, each of thickness $h_{k}$, that are stacked along the thickness direction $z$. The generic $k^{\text {th }}$ ply is thus delimited by the coordinates $z_{k}^{b}$ and $z_{k}^{t}$ identifying the bottom (superscript $b$ ) and top (superscript $t$ ) surfaces of the ply, respectively, see Fig. 1(b). Two local coordinates can be introduced for each ply: the local coordinate $z_{k} \in\left[z_{k}^{b}, z_{k}^{t}\right]$ and the dimensionless local coordinate $\zeta_{k}=2\left(z_{k}-z_{0 k}\right) / h_{k} \in[-1,1]$, where $z_{0 k}=\left(z_{k}^{t}+z_{k}^{b}\right) / 2$ is the coordinate of the mid-surface of the $k^{\text {th }}$ ply.

The perfect bond condition between adjacent plies requires the continuity of the displacement vector $u_{i}=\left[\begin{array}{lll}u_{1} & u_{2} & u_{3}\end{array}\right]^{T}$ and of the stress vector $\sigma_{i 3}$ composed of the three transverse stress com-

ponents $\sigma_{i 3}=\left[\begin{array}{lll}\sigma_{13} & \sigma_{23} & \sigma_{33}\end{array}\right]^{T}$, i.e., $u_{i k}^{t}=u_{i(k+1)}^{b}$ and $\sigma_{i 3 k}^{t}=\sigma_{i 3(k+1)}^{b}$. In the expressions above and throughout the paper, superscript $T$ denotes transposition and index $i \in(1,2,3)$ identifies the three Cartesian coordinates $x, y, z$. These conditions, that are a direct consequence of the Effective Modulus Theory, lead to the so-called $C_{z}^{0}$-requirements for the through-thickness modeling assumptions for the displacement and transverse stress fields [39]: the Interlaminar Continuity (IC) of the transverse stresses at a bi-material interface can in general be satisfied only by a displacement field that has a slope discontinuity (Zig-Zag, ZZ) at the interface. In the following, the various plate models formulated by means of Carrera's Unified Formulation are briefly introduced with special reference to the satisfaction of the $C_{z}^{0}$-requirements. 


\section{ACCEPTED MANUSCRIPT}

\subsection{Plate models in Carrera's Unified Formulation}

Carrera's Unified Formulation (CUF) consists in a compact index notation that permits to formulate many different plate models in a unified manner by introducing different assumptions for the through-thickness behavior of the structure [38]. The approximations are introduced for displacement variables only or for both displacement and transverse stress variables. In the former case, classical displacement-based models are developed by referring to the weak form related to the Principle of Virtual Displacements (PVD). In the latter case, advanced partially mixed models are formulated in the framework of Reissner's Mixed Variational Theorem (RMVT) [40], that is a variational statement expressly dedicated to the fulfillment of the IC conditions in laminated plate models [41]. In a PVD approach all stresses are evaluated from Hooke's law through the geometrically compatible strain field, which entails the violation of the IC at bi-material interface. On the contrary, the RMVT approach permits to introduce a transverse stress field that is independent of the strain field and it can be hence chosen so to exactly ("a priori") enforce the continuity of these stresses at the interfaces.

The approximations can be introduced for the whole laminate, which leads to an ESL description, or for each layer independently, which leads to a LW description. In CUF, the transverse stress variables are always described in an LW sense because of the local, material-dependent nature of the stresses. For the displacement unknowns, the choice between ESL and LW is let free.

The ESL description of the displacement field is represented by the following through-thickness distribution that holds over the whole laminate thickness $(z \in[-h / 2, h / 2])$ :

$u_{i}(x, y, z)=\sum_{s=0}^{N} F_{s}(z) \hat{u}_{i s}(x, y)$

where $\hat{u}_{i s}$ is the vector of $3(N+1)$ unknown functions that does not depend on the number of layers in the laminate. The approximating functions $F_{s}(z)$ are here chosen to be Taylor polynomials, i.e., $F_{s}(z)=z^{s}$. This approximation is of class $C^{N}$ in $z$, which means that it fulfills the Interlaminar Continuity (IC) but the Zig-Zag (ZZ) behavior at bi-material interfaces is violated. To overcome 


\section{ACCEPTED MANUSCRIPT}

this limitation, the highest-order term of the Taylor expansion, $F_{N}(z) \hat{u}_{i N}$ can be replaced by Murakami's Zig-Zag Function $(\mathrm{MZZF}) F_{Z Z}\left(\zeta_{k}(z)\right)=(-1)^{k} \zeta_{k}$ and the corresponding ESL unknown function $\hat{u}_{i z z}$. This way, the resulting through-thickness approximation has a slope discontinuity at the interfaces.

The LW description of the displacement field is given by

$$
\begin{aligned}
u_{i}^{k}(x, y, z) & =\sum_{s=0}^{N} F_{s}\left(\zeta_{k}(z)\right) \hat{u}_{i s}^{k}(x, y) \\
& =F_{b}\left(\zeta_{k}\right) \hat{u}_{i b}^{k}(x, y)+F_{t}\left(\zeta_{k}\right) \hat{u}_{i t}^{k}(x, y)+\sum_{r=2}^{N} F_{r}\left(\zeta_{k}\right) \hat{u}_{i r}^{k}(x, y)
\end{aligned}
$$

where the approximation is introduced for each ply separately (superscript $k$ ) so that the number of unknown functions $\hat{u}_{i s}^{k}$ is now dependent on the number of layers in the laminate. Legendre polynomials are used as interpolation functions $F_{s}\left(\zeta_{k}\right)$ and are illustrated in Fig. 2. Note that the

first approximation $(N=1)$ corresponds to the linear Lagrange interpolation that is only function of the bottom $(b)$ and top $(t)$ variables: since top and bottom unknown functions are available at each ply, it is straightforward to account for the IC within a standard assembly scheme. The same LW approximation is introduced for the transverse stress unknowns in the case of RMVT-based models.

In CUF, all variables are expanded with same order $N$; for a generalization of this formulation the reader is referred to the works of Demasi $[42,43]$. In this work, linear $(N=1)$ up to fourthorder $(N=4)$ polynomials are used for all independent variables (i.e., $u_{i}$ for classical PVD-based models and $u_{i}$ and $\sigma_{i 3}$ for advanced RMVT-based models). Note that the full 3D constitutive law is used in all CUF models.

All CUF models are implemented as User Element in Abaqus as isoparametric four-node plate elements based on a bilinear Lagrangian interpolation of all unknown functions, see Fig. 3. For classical PVD-based models, these are $\hat{u}_{i s}(x, y)$ for an ESL description and $\hat{u}_{i s}^{k}(x, y)$ for an LW description. For RMVT-based models, the same bilinear approximation is used for the LW trans-

\section{ACCEPTED MANUSCRIPT}




\section{ACCEPTED MANUSCRIPT}

verse stress unknowns $\hat{\sigma}_{i 3 s}^{k}(x, y)$. All stiffness contributions are computed exactly through Gaussian quadrature.

A solid (3D) FEM model will be used for comparison purposes, which is computed with the commercial software Ansys. Each of the possible models is identified by a unique acronym, which is indicated in Tab. 1 along with their capability to fulfill a priori the Interlaminar Continuity of the transverse stress field (IC) and the Zig-Zag behavior of the displacement field at the interfaces (ZZ). Note that PVD-based models, such as ED, LD as well as the standard (displacement) FEM, cannot satisfy exactly the IC conditions for the transverse stresses. Tab. 1 also reports the number of unknowns per node of the in-plane mesh (NDOF) as a function of the expansion order $N$ and the number of layers $N_{l}$. For a 3D model of Ansys with quadratic interpolation, for each node in the mid-plane the NDOF depends on the number $N_{e z}$ of elements used to discretize the thickness of each ply.

\subsection{Problem description and finite element model}

This work considers symmetric four-layered and eight-layered composite plates and focuses on the free-edge effect appearing under longitudinal extension (the classical Pipes-Pagano problem) and bending. The material properties of the orthotropic plies are reported in Tab. 2. With reference to Fig. 1(a), the geometry of the plate is defined by $a=2 b=8 h$ unless otherwise stated. All plies have the same thickness $h_{k}$, where $h_{k}=1 \mathrm{~mm}$ is taken for all numerical computations. The boundary conditions for the considered case studies are schematically illustrated in Fig. 4: for the extensional load case, a uniform axial strain $\epsilon_{0}$ is applied via a pre-described longitudinal displacement at $x= \pm a$, see Fig. 4(a); for the bending case, the plate is simply supported at its edges $x= \pm a$ and is loaded by a uniform pressure load $q_{0}$ at its top surface, see Fig. 4(b). In either case, a traction-free condition is present at the edges $y= \pm b$ :

$\sigma_{y y}(x, y= \pm b, z)=\sigma_{x y}(x, y= \pm b, z)=\sigma_{y z}(x, y= \pm b, z)=0$ 


\section{ACCEPTED MANUSCRIPT}

Since the CUF elements are plate elements, only an in-plane (2D) discretization is required: $N_{e x}$ is the number of elements along the longitudinal axis and $N_{e y}$ that along the width. A spacing ratio is applied to the elements' nodes in order to densify the mesh towards the free-edge. Two different FE meshes will be used, both being symmetric with respect to the $x$ and $y$ axes:

- Mesh I is illustrated in Fig. 5(a) and is made of $32 \times 32$ elements $\left(N_{e x}=N_{e y}=32\right)$; two spacing ratios are used for the $x$ and $y$ direction for having the smallest element at the plate center $(x=0)$ and at the free edges $(y= \pm b)$.

- Mesh II still has a spacing ratio that densifies the mesh towards the center $(x=0)$, but it subdivides the width direction into 2 partitions as schematically illustrated in 5(b): a large region that occupies $98.75 \%$ of the half-width $b$ (which corresponds to a size of $15.9 h_{k}$ as $b=4 h=16 h_{k}$ ) and a small region at the boundary of size $0.1 h_{k}$, which represents only $1.75 \%$ of the half-width $b$. The total number of elements is still given by $N_{e x} \times N_{e y}$, where now $N_{e y}=N_{e y}^{i n}+N_{e y}^{b r}, N_{e y}^{i n}$ and $N_{e y}^{b r}$ being the number of elements along the width used for the interior region and the boundary region, respectively. Both regions are discretized with a spacing ratio along the $y$ direction that densifies the mesh toward the free edges.

The 3D model employed for reference computation with the commercial FE software Ansys is based on the same in-plane mesh, but additionally $N_{e}$ elements are used to discretize the thickness of each ply. A spacing ratio is here introduced in order to densify the mesh towards the ply interfaces. Quadratic 20-node brick elements are used for the Ansys model. The parameters for Mesh I and Mesh II employed for the two case studies (extensional and bending load) are summarized in Tab. 3 . 


\section{ACCEPTED MANUSCRIPT}

\section{Validation of models}

The models from the CUF are first validated for the two loading configurations by referring only to the fourth-order ESL and LW models. Reference results are extracted from open literature and from 3D FE results obtained by Ansys. For the distributions along the width at bi-material interfaces, the transverse stresses $\sigma_{i 3}$ from PVD models are evaluated at the bottom ply of the interface. It is emphasized that, in classical displacement models, all stresses are directly obtained from the constitutive law, i.e., no integration of indefinite equilibrium equations is employed. Advanced models based on RMVT provide transverse stresses direct as nodal unknowns.

\subsection{Free-edge effect under extensional loading}

The composite plate is subjected to a uniform axial strain $\epsilon_{0}=1$. If not stated otherwise, all stress results are given in GPa. Two four-layered symmetric laminates are considered, the angleply $[ \pm 45]_{s}$ and the cross-ply $[0,90]_{s}$. The symmetry of the layup is exploited by modeling only the upper half of the laminate. All results are obtained with the discretization referred to as Mesh I. Note that the stress values provided by Wang and Crossman [13] at the free edge $(y=b)$ are actually located at $y=0.9985 b$.

Angle-ply Fig. 6(a) reports the evolution of the transverse shear stress $\sigma_{x z}$ along the half-width at the bi-material $( \pm 45)$ interface located at $z=h / 4$. The sharp increase of the transverse shear stress towards the free edge $y=b$ is seen. Both LW models agree well with the solutions of Wang and Crossman [13] and Davì and Milazzo [26] as well as with the 3D FE results of Ansys. ESL models do not reach the high stress value at the free edge. Fig. 6(b) reports the distribution of $\sigma_{x z}$ through the thickness at the free edge. It is apparent that ESL models are not able to capture any stress gradients occurring at the bi-material interface because they can only represent an average distribution. 


\section{ACCEPTED MANUSCRIPT}

Cross-ply The evolution of the transverse normal stress $\sigma_{z z}$ along the half-width at the bimaterial $(0,90)$ interface is reported in Fig. 7(a). Results from classical PVD-based and advanced RMVT-based models are reported in separated graphs. The free-edge effect is clearly visible through the steep increase of the stress. An excellent agreement is found between the LW models and the 3D results by Ansys, which are slightly different compared to those by Wang and Crossman [13]. The worst results are obtained by the classical, high-order ED4 model. The distribution through the thickness of $\sigma_{z z}$ is given in Fig. 7(b) and confirms the good agreement between LW models and the reference solutions. ESL models yield only averaged distributions which, however, provide a less erroneous result at the bi-material interface compared to the results reported for the angle-ply laminate (Fig. 6(b)). Moreover, Fig. 7(b) shows that PVD models do not exactly fulfill the IC condition and provide a discontinuity of $\sigma_{z z}$ at the bi-material interface.

\subsection{Free-edge effect under bending loading}

This case study, illustrated in Fig. 4(b), has been proposed by Tahani and Nosier [31] and concerns a plate whose dimensions are defined by $a=2 b=10 h\left(h_{k}=1 \mathrm{~mm}\right.$ is again considered $)$. The fourply $[0,90]_{s}$ laminate is loaded by a uniform pressure load $q_{0}=1 \mathrm{GPa}$. Due to the bending load, the whole laminate has to be modeled, i.e., the layup symmetry cannot be exploited to reduce the computational model. It is noted that, due to the thickness of the plate, no shear locking appears when using the CUF plate elements. Mesh I discretization has been used.

Fig. 8(a) reports the evolution along the half-width of the transverse shear stress $\sigma_{y z}$ evaluated at the mid-surface $(z=0)$ and at the upper $(0,90)$ interface located at $z=h / 4$. This stress component shows a steep rise in vicinity of the free edge, where however it has to vanish due to the tractionfree conditions. The good agreement between the LW models and the reference results is again apparent. As in the extension case, ESL models underestimate the characteristic gradients and, additionally, they fail to capture the substantially different behavior at the mid-surface and at the 


\section{ACCEPTED MANUSCRIPT}

bi-material interface. The through-thickness distribution of the transverse normal stress $\sigma_{z z}$ at the free edge is reported in Fig. 8(b), which confirms the excellent performance of the LW models and the difficulties of ESL models to follow the gradients induced by the bi-material interfaces.

\section{Stress Singularity}

Within the linear elastic Effective Modulus Theory approach, the bi-material interfaces at the free edge are expected to introduce singularities in the unbounded interlaminar stress components. This should result in rising stress values with a refinement of the FE mesh. For the CUF elements two refinements are actually possible: a refinement of the in-plane FE mesh and a refinement along the thickness by subdividing each ply into several mathematical layers.

Fig. 9 shows the effect of the FE mesh refinement on two transverse stress distributions: Fig. 9(a) reports the evolution along the half-width of the transverse shear stress $\sigma_{x z}$ for the $[ \pm 45]_{s}$ laminate under longitudinal strain $\epsilon_{0}$ and Fig. 9(b) the through-thickness distribution of $\sigma_{z z}$ for the $[0,90]_{s}$ laminate under the bending load $q_{0}$. In either case no significant rise of the stress level can be observed: it appears that the high-order LW plate elements do not recognize any stress singularity upon a refinement of the in-plane FE mesh.

The role of a refinement through-the-thickness is next considered: Mesh I is used and each ply is subdivided into a variable number of mathematical layers. The same approach proposed by Saeedi et al. [30] for their high-order plate model is here followed, which suggests to refine the mathematical layers towards the ply's interfaces. Note that the 3D Ansys model follows this approach as well, by employing a spacing ratio for the discretization along the thickness (see Tab. 3). The results obtained with LD4 elements are reported in Fig. 10. The current implementation of LM4 elements requires excessive RAM to perform the computations with large number of layers. The effect on the half-width evolution of $\sigma_{z z}$ for the angle-ply laminate in extension, Fig. 10(a), shows a clear increase in the stress level at the free edge. The effect on the through-thickness distri-

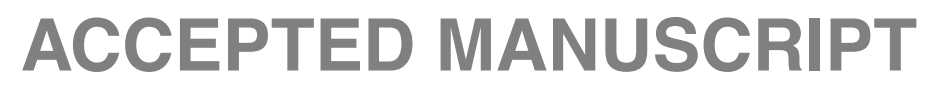




\section{ACCEPTED MANUSCRIPT}

bution at the free edge for cross-ply in bending is illustrated in Fig. 10(b) and shows that including mathematical layers enhances the satisfaction of the IC condition and of the traction conditions at the top and bottom surfaces of the laminate $\left(\sigma_{z z}(z=h / 2)=q_{0}\right.$ and $\left.\sigma_{z z}(z=-h / 2)=0\right)$.

The increase in the stress level observed in Fig. 10(a) suggests the presence of a singularity and the following analysis is focused on the stress response at a very close distance to the free edge. Therefore, subsequent analyses are performed with the discretization scheme referred to as Mesh II (see Tab. 3) and the normalized distance $r$ from the free edge and along the interface is introduced as

$r(y)=\frac{b-y}{h_{k}} \quad$ where $\left\{\begin{array}{l}y \in\left[b-h_{k}, b\right] \\ r \in[1,0]\end{array}\right.$

For small distances $r$, the singular stress behavior can be represented as [14, 26]

$\sigma_{i j}(r) \approx A_{i j} r^{-\alpha_{i j}} \quad$ with $\left.\left.r \in\right] 0,1\right]$ and $\alpha_{i j} \in[0,1]$

or, equivalently, as

$\log \sigma_{i j}(r) \approx \log A_{i j}-\alpha_{i j} \log r$

where $\alpha_{i j}$ is the singularity power and $A_{i j}$ the singularity strength, which can be related to a stress intensity factor. According to Eq. (5b), the log-log plot of $\sigma_{i j}(r)$ would be a line of slope $-\alpha_{i j}$ and $\sigma$-intercept at $r=1$ of $A_{i j}$. This representation should be applied to those stress components that are continuous at the interface ( $r$ runs along the interfaces) and that are unbounded at the free edge, i.e., $\sigma_{x z}$ (for angle-ply laminates only) and $\sigma_{z z}$.

Fig. 11(a) presents a zoom of the distributions along the width of $\sigma_{x z}$ limited to the range $1 \leq$ $r \leq 0$, obtained with various models for the angle-ply laminate subjected to extension; Fig. 11(b) presents the same results in log-log scale for the range $5.10^{-4} \leq r \leq 10^{-1}$. It can be seen that the refinement needs to be increased further in order to recover the linear behavior (in the $\log -\log$ scale) of Davì and Milazzo [26] in the whole interval. However, convergence appears to be reached 


\section{ACCEPTED MANUSCRIPT}

in the range $10^{-2} \leq r \leq 10^{-1}$. Therefore, the parameters $A_{x z}$ and $\alpha_{x z}$ can be evaluated via a leastsquares fitting from the FE results at the nodes inside this interval. In an attempt to enlarge this interval upon increasing the resolution next to the interfaces, Lagrange polynomials interpolated at Chebyshev nodes [44] have been used instead of the standard Legendre polynomials of CUF. However, no relevant improvement could be remarked for the present application.

The convergence of the values of the singularity power and strength with increasing number of mathematical layers is reported in Fig. 12. The plots highlight that the values extracted from the CUF elements converge towards the 3D solution of Ansys. Comparison with the BEM solution of Davì and Milazzo [26] shows a very good agreement for the singularity strength $A_{x z}$ and a difference of about $10 \%$ for the singularity power $\alpha_{x z}$. It is noted that very different values have been predicted for the singularity power by means of quasi-analytic approaches [22]. Note also that due to RAM limitations, only 2 mathematical layers can be presently used for the LM4 model, for which convergence is not achieved, see Fig. 12.

\section{Assessments using singularity parameters}

Based on the singularity parameters, an assessment of the behavior of the different CUF models for both extension and bending loading is proposed. The geometry of the plate is here coincident with that of the classical Pipes-Pagano example and Mesh II is employed to extract the singularity parameters from the nodal stress values located in the range $10^{-2} \leq r \leq 10^{-1}$. In order to have comparable results between the extensional load and the bending load, the magnitude of the uniform load $q_{0}$ is chosen so to produce the same total deformation energy in the laminate as in the extension load case. The evaluation of the total deformation energy is provided by the 3D Ansys FE model. Tab. 4 reports the magnitudes of the uniform pressure load $q_{0}$ for the various symmetric laminates considered in this Section, i.e., the 4-ply $[ \pm 45]_{s}$ and $[0,90]_{s}$ laminates as well as the 8-ply quasi-isotropic laminates $[ \pm 45,0,90]_{s}$ and $[90,0, \pm 45]_{s}$. In order to provide a consistent 


\section{ACCEPTED MANUSCRIPT}

comparison between all LW, i.e., the $\mathrm{LDN}, \mathrm{LM} N$ and $\mathrm{EM} N$ models, only 2 mathematical layers are used in this section, even if the results in the previous Section indicate that this solution may not be converged.

\subsection{Symmetric 4-ply laminates}

The power law characterized by the singularity parameters obtained for $\sigma_{x z}$ in the $[ \pm 45]_{s}$ angleply laminate are graphically displayed in Fig. 13, those for $\sigma_{z z}$ in the $[0,90]_{s}$ cross-ply laminate in Fig. 14. The left and right graphs of each figure report the results for the extension and the bending load, respectively. In order to ease the comparison between the two loading conditions, the same axes range is used for the log-log scales. As a consequence, some curves may not be visible because they lie outside of the selected range.

By taking the Ansys 3D FE results as reference, the results show clearly the superiority of LW descriptions over ESL ones, which systematically underestimate the singularity power $\alpha_{i j}$. Moreover, better results are obtained for high-order polynomial expansion $N$. It appears that the introduction of the Zig-Zag function does not enhance the overly poor response of ESL models. No enhancement can be expected from ESL models upon introducing mathematical layers. It is further emphasized that MZZF is completely useless if fictitious interfaces are introduced through the use of mathematical layers because the Zig-Zag term vanishes. Advanced ESL models, such as EM4, EM2 and EMz2, have an LW description of the transverse stresses but these models result to be practically insensitive with respect to a refinement through mathematical layers because of the ESL displacement field. Classical displacement-based models and advanced RMVT-based models show comparable results. This means that no real improvement is obtained in terms of singularity parameters if mixed models are used that exactly fulfill the IC condition, exception made for the advantage of having a unique transverse stress value at the interfaces. It is finally noted that, in general, if the singularity power is underestimated $\left(\alpha_{\text {model }}<\alpha_{\text {ref }}\right)$, then the singularity strength 


\section{ACCEPTED MANUSCRIPT}

results overestimated $\left(A_{\text {model }}>A_{\text {ref }}\right)$, and vice-versa.

Concerning the comparison between the free-edge effect induced by the extension and the bending load, it may be concluded that the angle-ply laminate has a higher singularity strength in extension than in bending, while the opposite holds true for the cross-ply laminate. However, for the cross-ply laminate the singularity power appears to be larger in extension than in bending.

\subsection{Quasi-isotropic laminates}

Based on the singularity parameters $\left|A_{i j}\right|$ and $\alpha_{i j}$, a comparison between the various interfaces that characterize two symmetric quasi-isotropic laminates is proposed. Both extension $\left(\epsilon_{0}\right)$ and bending under uniform pressure load $\left(q_{0}\right)$ are considered. Results for unbounded interlaminar stress components $\sigma_{z z}$ and $\sigma_{x z}$ are obtained using the LD4 model with two mathematical layers per ply.

The quasi-isotropic laminate $[ \pm 45,0,90]_{s}$ is first considered (Fig. 15) and the interlaminar stresses are evaluated at the following three interfaces, starting from the symmetry plane: the $(0,90)$ cross-ply interface, the $(-45,0)$ interface and the $( \pm 45)$ angle-ply interface. The results are reported in Fig. 15(a) for the extension load and in Fig. 15(b) for the bending load. The strongest singularity appears to occur for $\sigma_{z z}$ at the $(0,90)$ interface. Note that at the same interface, no singularity is present for the transverse shear stress $\left(\alpha_{x z}=0\right)$. Considering the angle-ply interface, it is worth remarking that the singularity power of $\sigma_{x z}$ and $\sigma_{z z}$ are not the same $\left(\left|\alpha_{z z}\right|>\left|\alpha_{x z}\right|\right)$, and that the singularity strength is higher for the transverse shear stress $\sigma_{x z}\left(\left|A_{x z}\right|>\left|A_{z z}\right|\right)$. As far as the free-edge effect under bending load is concerned, it appears that the strongest singularity is associated to $\sigma_{x z}$ at the angle-ply interface and that its strength is smaller than in the extension case.

The quasi-isotropic $[90,0, \pm 45]_{s}$ laminate is next considered, see Fig. 16. The interlaminar stresses are reported for the two interfaces $(0,45)$ and $( \pm 45)$ (angle-ply interface). At the $(90,0)$ 


\section{ACCEPTED MANUSCRIPT}

cross-ply interface, the transverse shear stress shows no singularity and the transverse normal stress is not monotonous within the defined interval of $r$, which prevents the evaluation of the singularity parameters according to Eq. (5) [14]. Observing the free-edge effect arising under the extensional load, Fig. 16(a), it appears that the strongest singularity occurs at the angle-ply interface and concerns in equal way both stress components $\sigma_{x z}$ and $\sigma_{z z}$. In this case, the same singularity power is found for all stress components. The results for the bending load suggest that the strongest singularity is associated to the transverse normal stress $\sigma_{z z}$, irrespective of the interface. In this case, the singularity power of the interlaminar stresses taken at the one interface appears to be different. Finally, the comparison between the singularity strength in bending and extension indicates that the free-edge effects due to extension are higher than those induced by bending loads.

\section{Conclusion}

Classical and advanced, higher-order plate elements formulated according to Carrera's Unified Formulation (CUF) have been employed to the free-edge problems occurring in symmetric laminates subjected to extension (classical Pipes-Pagano problem) and bending. Unbounded interlaminar stresses have been represented through the classical power-law singularity approach and the extracted singularity parameters have been shown to converge towards the results obtained with a 3D FE model computed with Ansys. A subdivision of the plies into several mathematical layers is the key factor to allow high-order LW models to well capture the stress singularity. The presented 2D plate elements provide quasi-3D solutions and transverse stress singularities can be well evaluated. Since they require only a 2D mesh, these elements may be interesting for applications involving large FE models. Based on the singularity parameters, an assessment of various CUF models has been proposed leading to the conclusion that LW models are mandatory and that the use of mathematical layers is necessary for enhancing the accuracy. Furthermore, the free-edge effects due to bending and extension have been compared and it appears that the singularity strength is larger in

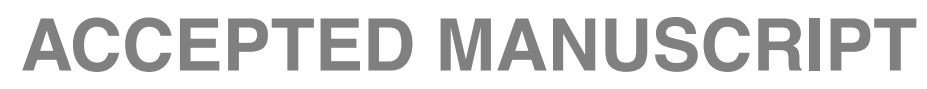




\section{ACCEPTED MANUSCRIPT}

extension than in bending.

Further developments are planned that concern a more thorough investigation of the advanced LMN models once the current RAM limitation is overcome by a more efficient User Element implementation. A submodeling technique involving the connection between kinematically incompatible plate models should permit a further reduction in the computational effort [10]. A quantitative criterion to establish mesh and model requirements for free-edge problems could be proposed based on the singularity parameters. Finally, despite the numerous works that addressed the free-edge problem, it appears that some key questions are still to be answered. In particular, the differences between the singularity powers predicted by semi-analytical approaches [22, 45] and those obtained from discrete numerical solutions $[14,26]$ are still to be explained. 


\section{ACCEPTED MANUSCRIPT}

\section{References}

[1] N. J. Pagano, G. A. Schoeppner, Delamination of polymer matrix composites: Problems and assessment, in: A. Kelly, C. Zweben (Eds.), Comprehensive Composite Materials, vol. 2, chap. 13, Elsevier, 433-528, 2000.

[2] J. N. Reddy, Mechanics of Laminated Composite Plates and Shells: Theory and Analysis, CRC Press, 2nd edn., 2004.

[3] E. Carrera, Theories and Finite Elements for Multilayered, Anisotropic, Composite Plates and Shells, Archives of Computational Methods in Engineering 9 (2) (2002) 87-140.

[4] E. Carrera, Historical review of Zig-Zag theories for multilayered plates and shells, Applied Mechanics Reviews 56 (3) (2003) 287-308.

[5] T. Kant, K. Swaminathan, Estimation of transverse/interlaminar stresses in laminated composites - a selective review and survey of current developments, Composite Structures 49 (2000) 65-75.

[6] K. Rohwer, S. Friedrichs, C. Wehmeyer, Analyzing laminated structures from fibrereinforced composite material - an assessment, Technische Mechanik 25 (1) (2005) 59-79.

[7] K. J. Saeger, P. A. Lagace, D. J. Shim, Interlaminar stresses due to in-plane gradient stress fields, Journal of Composite Materials 36 (2) (2002) 211-227.

[8] D. Robbins Jr, J. Reddy, Variable kinematic modelling of laminated composite plates, International Journal for Numerical Methods in Engneering 39 (1996) 2283-2317.

[9] F. Biscani, G. Giunta, E. Carrera, H. Hu, Variable kinematic plate elements coupled via Arlequin method, Composite Structures 91 (2012) 1264-1290. 


\section{ACCEPTED MANUSCRIPT}

[10] C. Wenzel, P. Vidal, M. D’Ottavio, O. Polit, Coupling of heterogenous kinematics and Finite Element approximations applied to composite beam structures, Composite Structures 116 (2014) 177-192.

[11] C. Mittelstedt, W. Becker, Free-Edge Effects in Composite Laminates, Applied Mechanics Reviews 60 (5) (2007) 287-308.

[12] R. Pipes, N. Pagano, Interlaminar Stresses in Composite Laminates Under Uniform Axial Extension, Journal of Composite Materials 4 (4) (1970) 538-548.

[13] A. Wang, F. Crossman, Some New Results on Edge Effect in Symmetric Composite Laminates, Journal of Composite Materials 11 (1) (1977) 92-106.

[14] I. S. Raju, J. H. Crews Jr, Interlaminar Stress Singularities at a Straight Free Edge in Composite Laminates, Computers \& Structures 14 (1-2) (1981) 21-28.

[15] S. Wang, R. Stango, Optimally discretized finite elements for boundary-layer stresses in composite laminates, AIAA Journal 21 (4) (1983) 614-620.

[16] R. Spilker, S. Chou, Edge effects in symmetric composite laminates: importance of satisfying the traction-free edge condition, Journal of Composite Materials 14 (1980) 2-20.

[17] P. Bar-Yoseph, J. Avrashi, On the nature of the free edge stress singularity in composite laminated plates, International Journal for Numerical Methods in Engneering 26 (1988) 15071523.

[18] G. Ghiringhelli, G. Sala, Influence of stacking sequences and interlaminar layer in stress singularitied at free edge of composite laminates, Meccanica 25 (1990) 32-39.

[19] L. Ye, Some Characteristics of Distributions of Free-Edge Interlaminar Stresses in Composite Laminates, International Journal of Solids and Structures 26 (3) (1990) 331-351. 


\section{ACCEPTED MANUSCRIPT}

[20] P. Bar-Yoseph, D. Ben-David, Free-edge effects in unsymmetrically laminated composite plates, Composite Structures 30 (1995) 13-23.

[21] P. Murthy, C. Chamis, Free-Edge Delamination: Laminate Width and Loading Condition Effects, Tech. Rep., NASA Lewis Research Center, Cleveland, Ohio, 1987.

[22] S. Wang, I. Choi, Boundary Layer Effects in Composite Laminates: Part 1 - Free-Edge Stress Singularities, Journal of Applied Mechanics 49 (1982) 541-548.

[23] S. Wang, I. Choi, Boundary Layer Effects in Composite Laminates: Part 2 - Free-Edge Stress Solutions and Basic Characteristics, Journal of Applied Mechanics 49 (1982) 549-560.

[24] C. Kassapoglou, P. A. Lagace, An Efficient Method for the Calculation of Interlaminar Stresses in Composite Materials, Journal of Applied Mechanics 53 (1986) 744-750.

[25] C. Kassapoglou, Determination of Interlaminar Stresses in Composite Laminates under Combined Loads, Journal of Reinforced Plastics and Composites 9 (1) (1990) 33-58.

[26] G. Davì, A. Milazzo, Boundary Element Solution for Free Edge Stresses in Composite Laminates, Journal of Applied Mechanics 64 (1997) 877-884.

[27] G. S. Ramtekkar, Y. M. Desai, On free-edge effect and onset of delamination in FRPC laminates using mixed finite element model, Journal of Reinforced Plastics and Composites 28 (3) (2009) 317-341.

[28] V.-T. Nguyen, J.-F. Caron, A new finite element for free edge effect analysis in laminated composites, Computers and Structures 84 (2006) 1538-1546.

[29] N. J. Pagano, Stress fields in composite laminates, International Journal of Solids and Structures 14 (1978) 385-400. 


\section{ACCEPTED MANUSCRIPT}

[30] N. Saeedi, K. Sab, J.-F. Caron, Delaminated multilayered plates under uniaxial extension. Part II: Efficent layerwise mesh strategy for the prediction of delamination onset, International Journal of Solids and Structures 49 (2012) 3727-3740.

[31] M. Tahani, A. Nosier, Edge effects of uniformly loaded cross-ply composite laminates, Materials \& Design 24 (2003) 647-658.

[32] D. Robbins Jr, J. Reddy, Modelling of thick composites using a layerwise laminate theory, International Journal for Numerical Methods in Engineering 36 (1993) 655-677.

[33] A. Nosier, A. Bahrami, Free-edge stresses in antisymmetric angle-ply laminates in extension and torsion, International Journal of Solids and Structures 43 (2006) 6800-6816.

[34] A. Nosier, A. Bahrami, Interlaminar stresses in antisymmetric angle-ply laminates, Composite Structures 78 (2007) 18-33.

[35] A. Nosier, M. Maleki, Free-edge stresses in general composite laminates, International Journal of Mechanical Sciences 50 (2008) 1435-1447.

[36] H. Y. Sarvestani, M. Y. Sarvestani, Free-edge stress analysis of general composite laminates under extension, torsion and bending, Applied Mathematical Modelling 36 (2012) 1570_ 1588.

[37] M. D’Ottavio, P. Vidal, E. Valot, O. Polit, Assessment of plate theories for free-edge effects, Composites: Part B 48 (2013) 111-121.

[38] E. Carrera, Theories and Finite Elements for Multilayered Plates and Shells: A Unified Compact Formulation with Numerical Assessment and Benchmarking, Archives of Computational Methods in Engineering 10 (3) (2003) 215-296.

[39] E. Carrera, $C_{z}^{0}$-Requirements - models for the two dimensional analysis of multilayered structures, Composite Structures 37 (3-4) (1997) 373-383. 


\section{ACCEPTED MANUSCRIPT}

[40] E. Reissner, On a certain mixed variational theorem and a proposed application, International Journal for Numerical Methods in Engneering 20 (1984) 1366-1368.

[41] E. Carrera, Developments, ideas and evaluations based upon Reissner's mixed variational theorem in the modeling of multilayered plates and shells, Applied Mechanics Reviews 54 (4) (2001) 301-329.

[42] L. Demasi, $\infty^{3}$ Hierarchy plate theories for thick and thin composite plates: The generalized unified formulation, Composite Structures 84 (3) (2008) 256-270.

[43] L. Demasi, $\infty^{6}$ Mixed plate theories based on Generalized Unified Formulation. Part I: Governing equations, Composite Structures 87 (2009) 1-11.

[44] G. Kulikov, S. Plotnikova, Exact 3D stress analysis of laminated composites by sampling surfaces method, Composite Structures 94 (12) (2013) 3654-3663.

[45] R. Zwiers, T. Ting, R. Spilker, On the logarithmic singularity of free-edge stresses in laminated composites under uniform extension, Journal of Applied Mechanics 49 (1982) 561569. 


\section{ACCEPTED MANUSCRIPT}

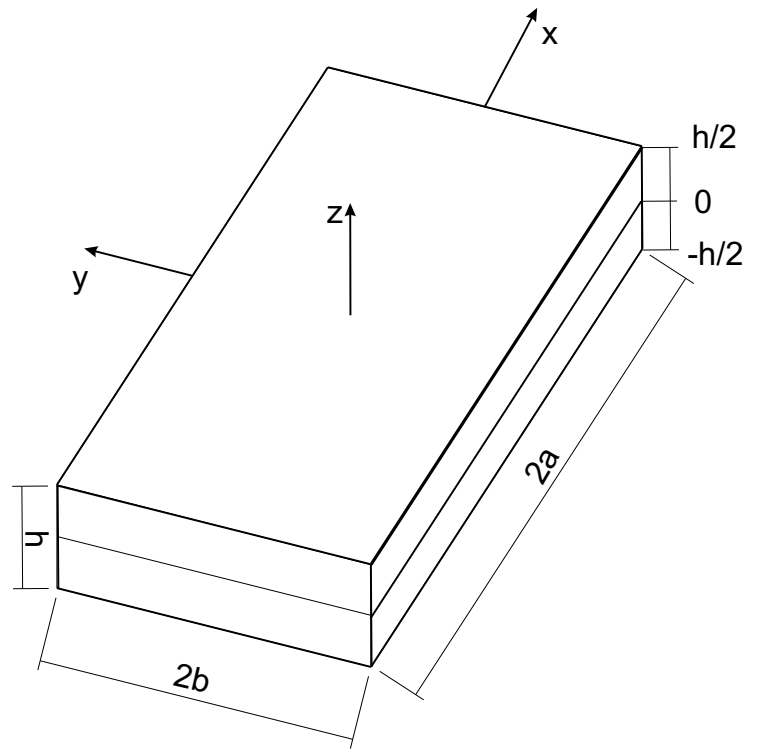

(a) Plate geometry

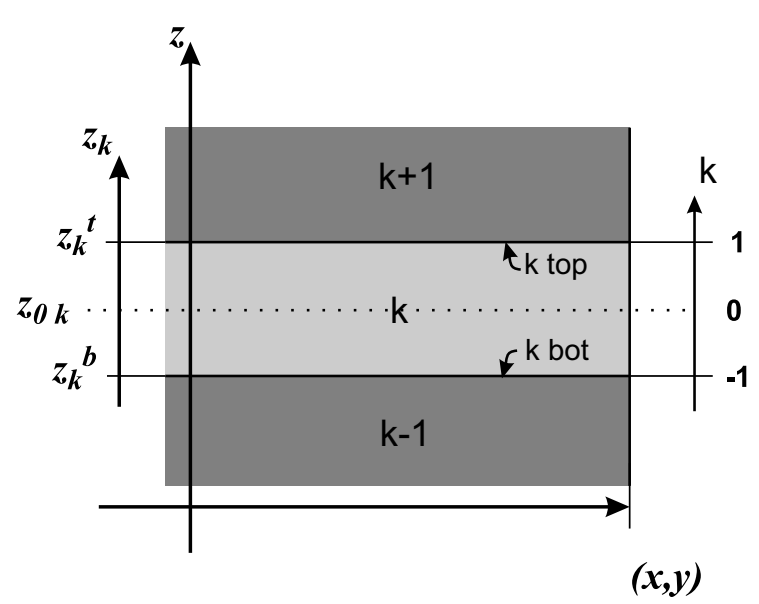

(b) Composite cross-section

Figure 1: Geometry and reference frames used for the description of the laminated plate 


\section{ACCEPTED MANUSCRIPT}

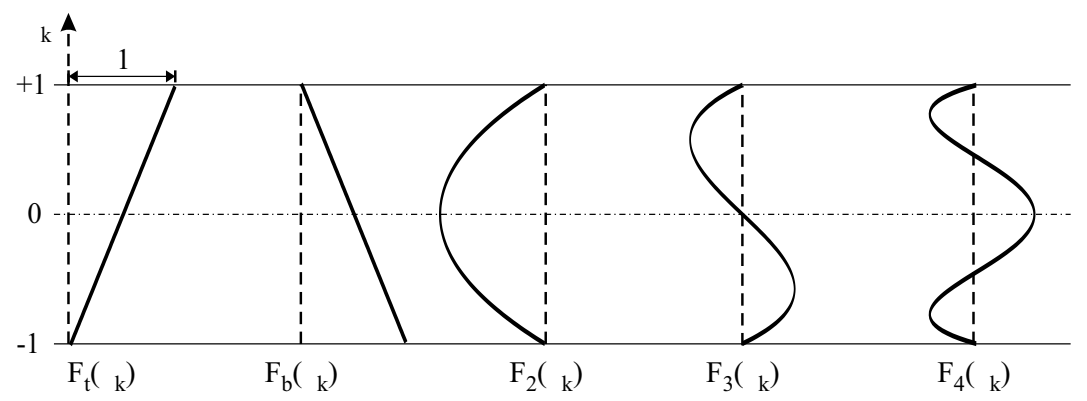

Figure 2: Through-thickness interpolation functions for LW descriptions 


\section{ACCEPTED MANUSCRIPT}

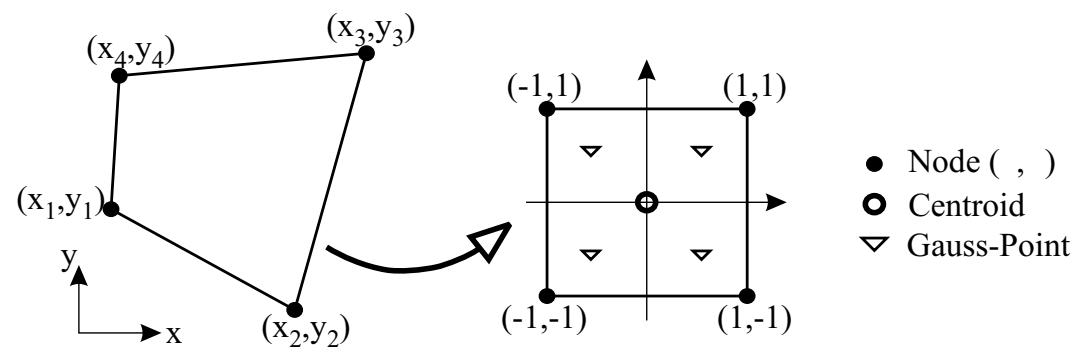

Figure 3: Isoparametric bilinear FEM interpolation for CUF elements 


\section{ACCEPTED MANUSCRIPT}

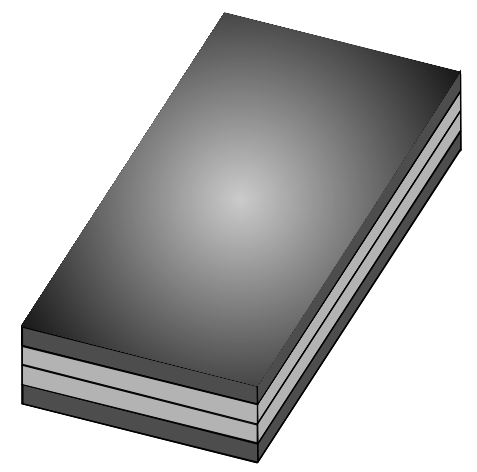

(a) Extensional configuration

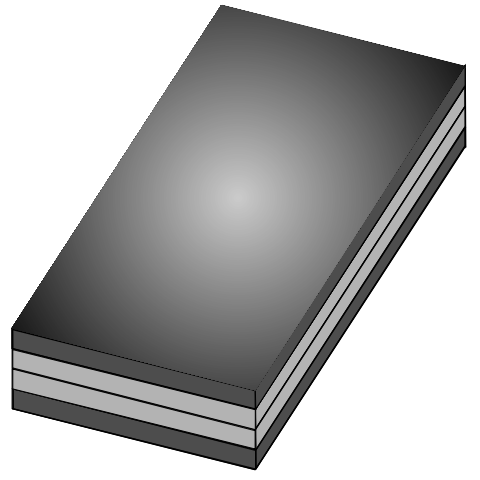

(b) Bending configuration

Figure 4: Case studies for the free-edge effect: laminates subjected to longitudinal extension (left) and bending (right) 


\section{ACCEPTED MANUSCRIPT}

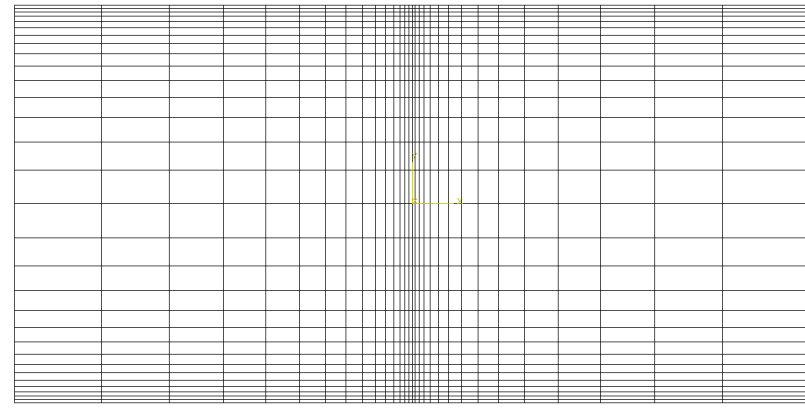

(a) Mesh I

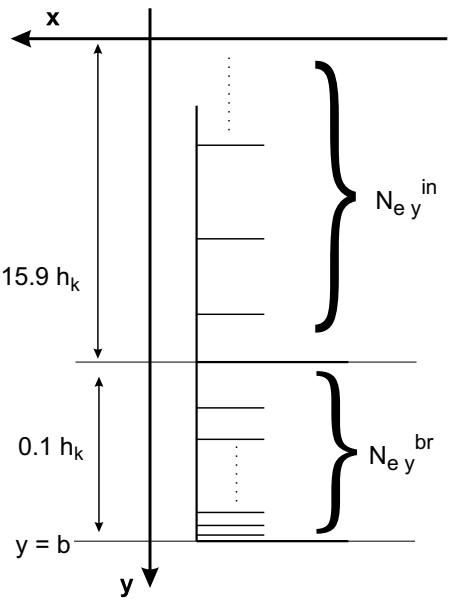

(b) Mesh II

Figure 5: Illustration of the employed discretization schemes: Mesh I (left) has a continuous refinement towards the free edges; Mesh II (right) subdivides the half-width into an interior region and a boundary region 


\section{ACCEPTED MANUSCRIPT}

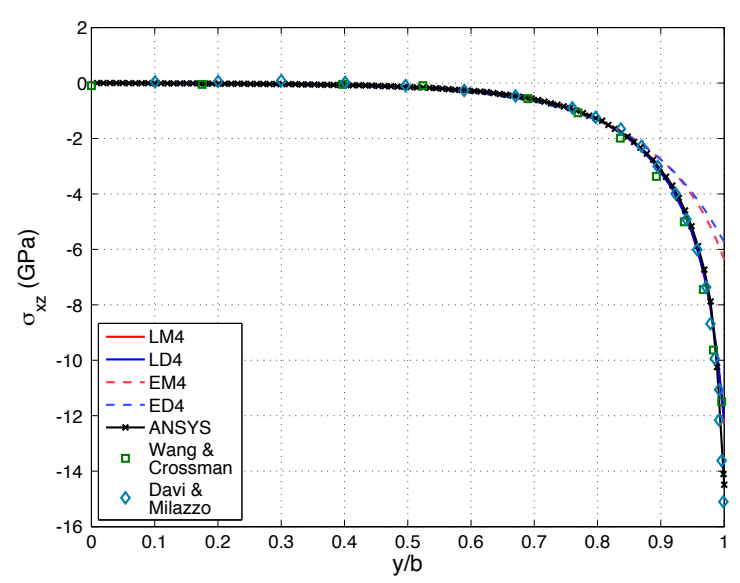

(a) $[ \pm 45]_{s}\left(\epsilon_{0}\right): \sigma_{x z}(x=0, y, z=h / 4)$

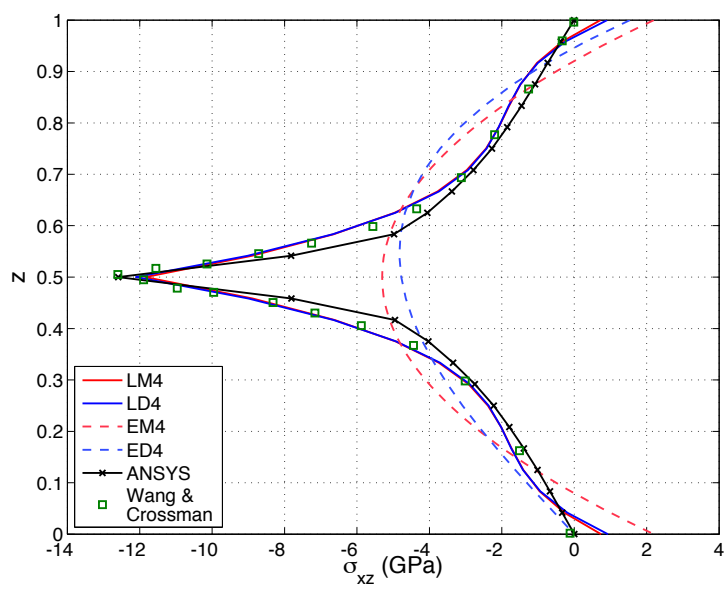

(b) $[ \pm 45]_{s}\left(\epsilon_{0}\right): \sigma_{x z}(x=0, y=b, z)$

Figure 6: Transverse shear stress for the $[ \pm 45]_{s}$ laminate under uniform axial extension: distribution along the width at the $( \pm 45)$ interface (left) and through the thickness at the free edge (right) 


\section{ACCEPTED MANUSCRIPT}
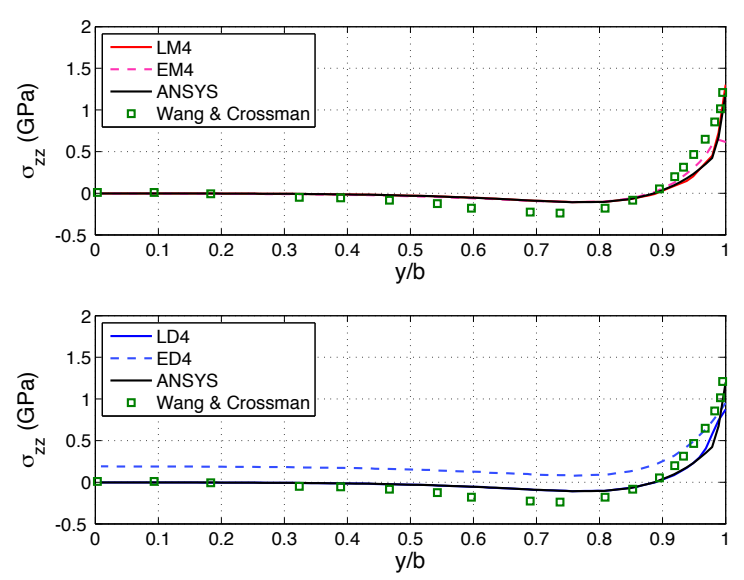

(a) $[0,90]_{s}\left(\epsilon_{0}\right): \sigma_{z z}(x=0, y, z=h / 4)$
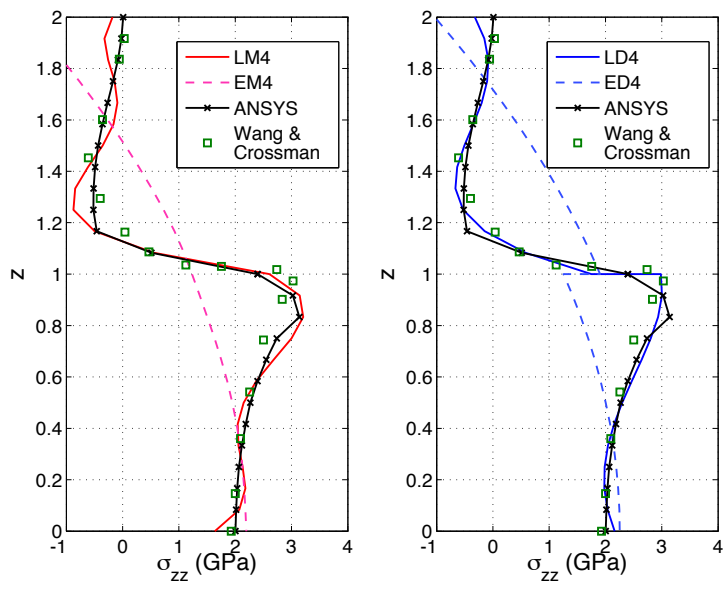

(b) $[0,90]_{s}\left(\epsilon_{0}\right): \sigma_{z z}(x=0, y=b, z)$

Figure 7: Transverse normal stress for the $[0,90]_{s}$ laminate under uniform axial extension: distribution along the width at the $(0,90)$ interface (left) and through the thickness at the free edge (right) 


\section{ACCEPTED MANUSCRIPT}
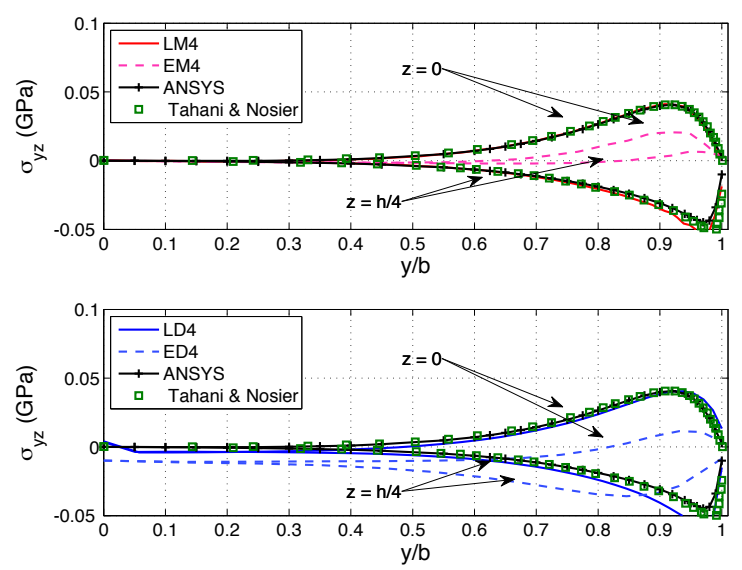

(a) $[0,90]_{s}\left(q_{0}\right): \sigma_{y z}(x=0, y=b, z=\{0, h / 4\})$
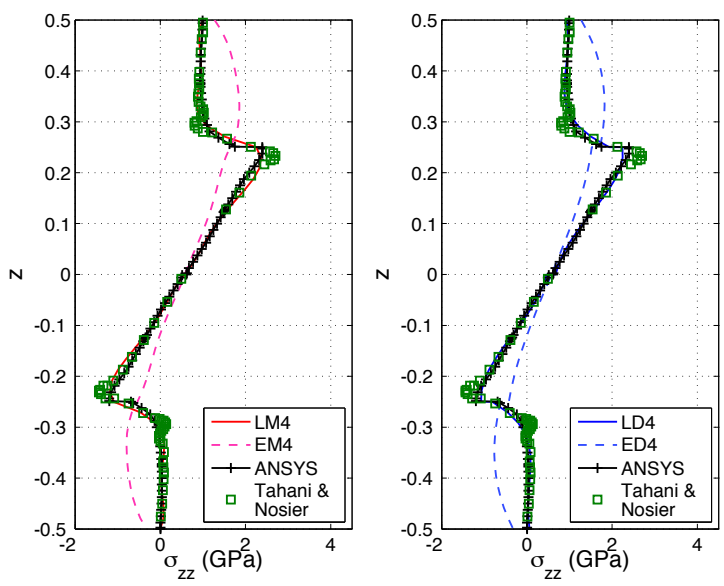

(b) $[0,90]_{s}\left(q_{0}\right): \sigma_{z z}(x=0, y=b, z)$

Figure 8: Transverse stresses for the $[0,90]_{s}$ laminate under uniform pressure load. Left: distribution of $\sigma_{y z}$ along the width at the mid-surface $((90,90)$ interface at $z=0)$ and at the bi-material interface $((0,90)$ interface at $z=h / 4)$; Right: distribution of $\sigma_{z z}$ through the thickness at the free edge. 


\section{ACCEPTED MANUSCRIPT}
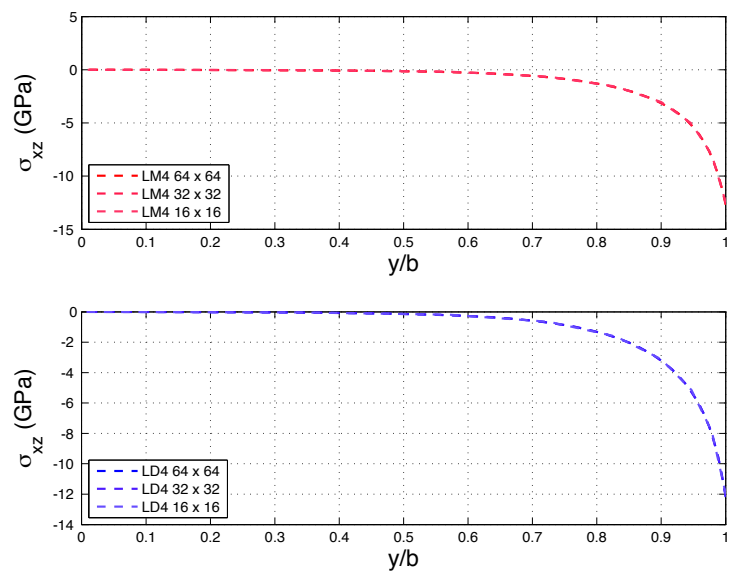

(a) $[ \pm 45]_{s}\left(\epsilon_{0}\right): \sigma_{x z}(x=0, y, z=h / 4)$
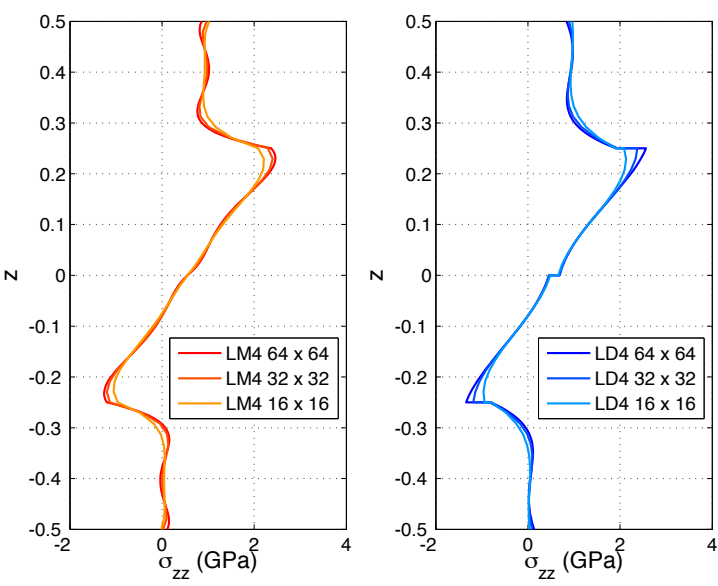

(b) $[0,90]_{s}\left(q_{0}\right): \sigma_{z z}(x=0, y=b, z)$

Figure 9: Effect of FE mesh refinement on the unbounded interlaminar stress components for a uniform extension load (left) and the bending load (right). 


\section{ACCEPTED MANUSCRIPT}

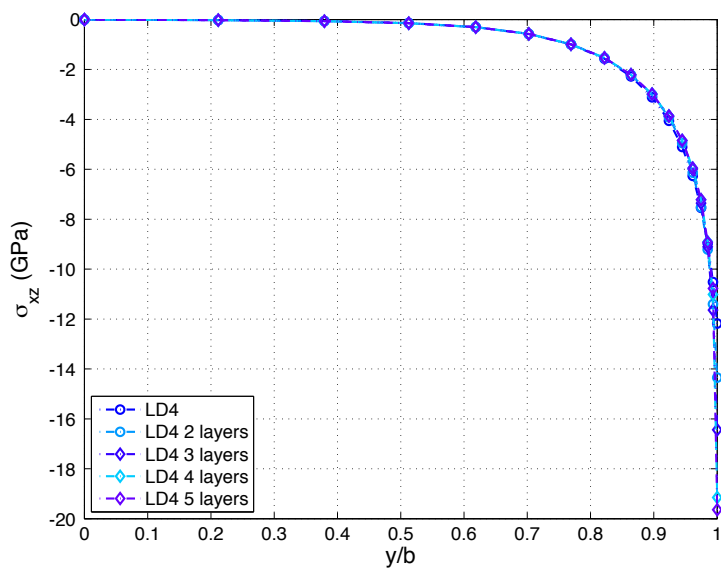

(a) $[ \pm 45]_{s}\left(\epsilon_{0}\right): \sigma_{x z}(x=0, y, z=h / 4)$

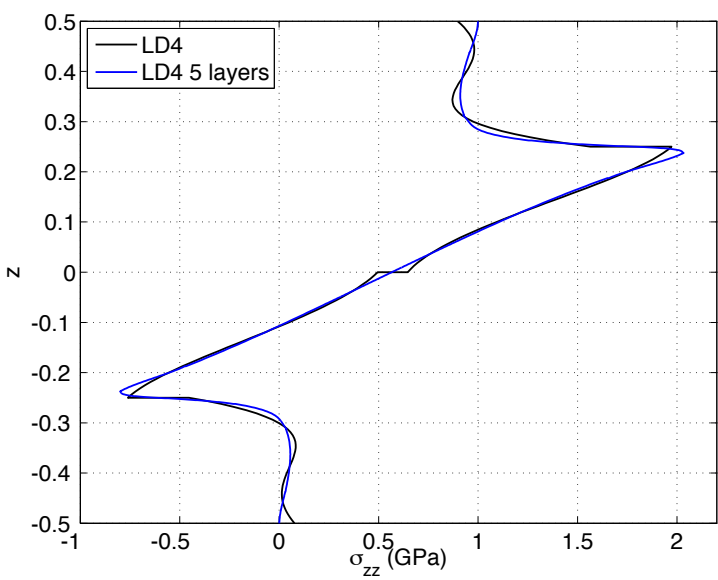

(b) $[0,90]_{s}\left(q_{0}\right): \sigma_{z z}(x=0, y=b, z)$

Figure 10: Effect of number of mathematical layers on the unbounded interlaminar stress components for a uniform extension load (left) and the bending load (right). 


\section{ACCEPTED MANUSCRIPT}

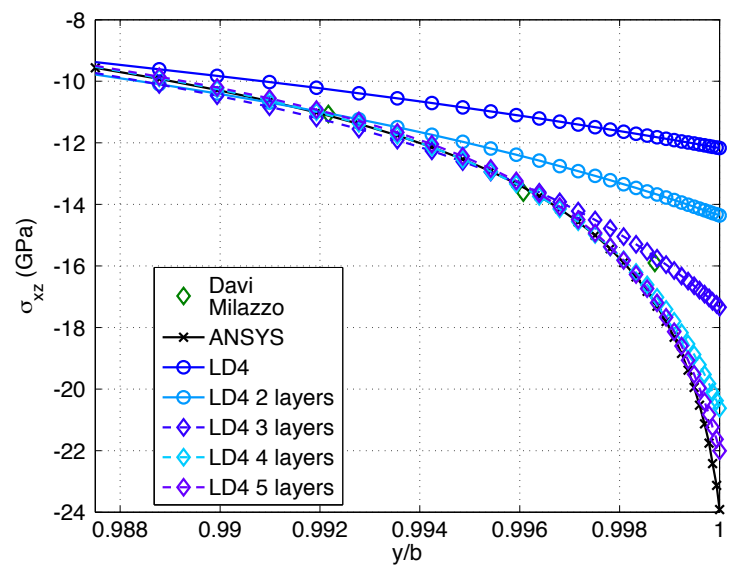

(a) $[ \pm 45]_{s}\left(\epsilon_{0}\right): \sigma_{x z}(x=0, y, z=h / 4)$

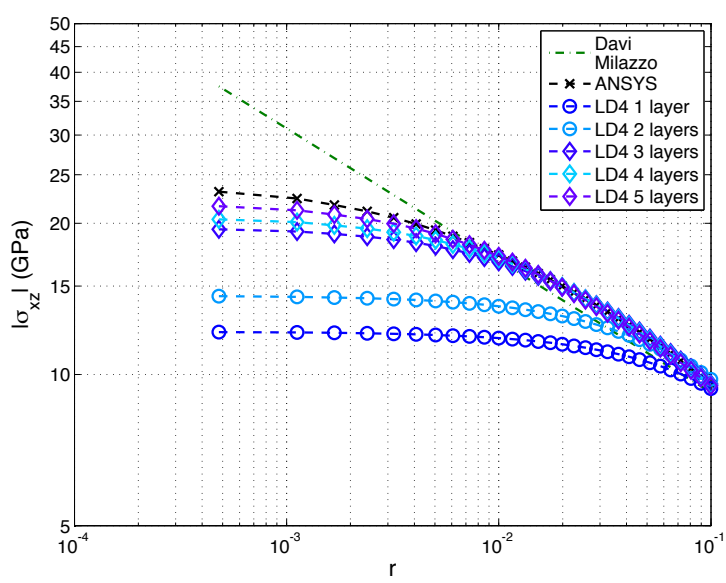

(b) log-log representation of Fig. 11(a)

Figure 11: Distribution of $\sigma_{x z}$ at the bi-material interface for the [ \pm 45$]$ laminate under extension load in immediate vicinity of the free edge (left) and its log-log representation (right). 


\section{ACCEPTED MANUSCRIPT}

\begin{tabular}{ccc}
\hline \hline Model & $\left|A_{x z}\right|[\mathrm{GPa}]$ & $\alpha_{x z}$ \\
\hline $1 \times$ LM4 & 7.0380 & 0.1460 \\
$2 \times$ LM4 & 6.2170 & 0.2123 \\
$1 \times$ LD4 & 6.9099 & 0.1399 \\
$2 \times$ LD4 & 6.3246 & 0.1979 \\
$3 \times$ LD4 & 4.9793 & 0.2894 \\
$4 \times$ LD4 & 4.9186 & 0.2920 \\
$5 \times$ LD4 & 4.9212 & 0.2895 \\
Ansys & 4.9758 & 0.2884 \\
Davì \& Milazzo & 5.0280 & 0.2630 \\
\hline \hline
\end{tabular}
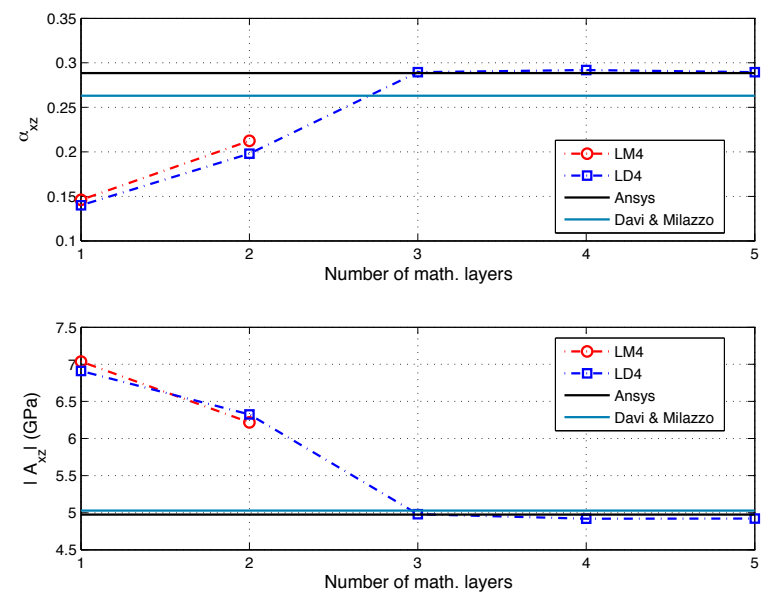

Figure 12: Convergence of singularity strength $\alpha_{x z}$ and power $A_{x z}$ with increasing number of mathematical layers $\left([ \pm 45]_{s}\right.$ laminate in extension $)$. 


\section{ACCEPTED MANUSCRIPT}

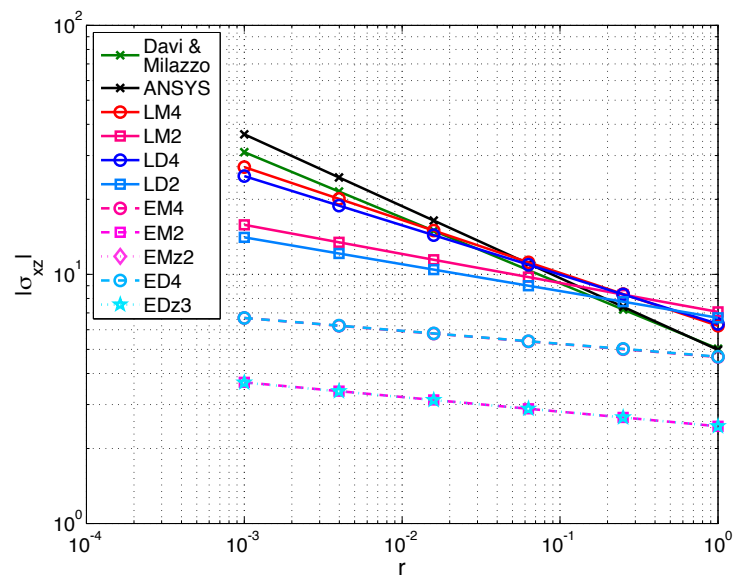

(a) $[ \pm 45]_{s}\left(\epsilon_{0}\right): \sigma_{x z}(x=0, r, z=h / 4)$

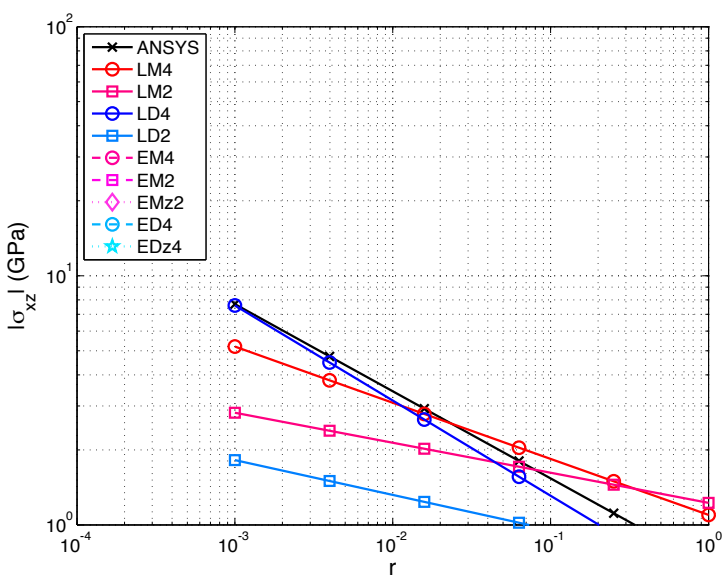

(b) $[ \pm 45]_{s}\left(q_{0}\right): \sigma_{x z}(x=0, r, z=h / 4)$

Figure 13: Transverse shear stress $\sigma_{x z}(r)$ response (log-log scale) for the $[ \pm 45]_{s}$ laminate under extension load (left) and bending load (right): assessment of different CUF models. 


\section{ACCEPTED MANUSCRIPT}

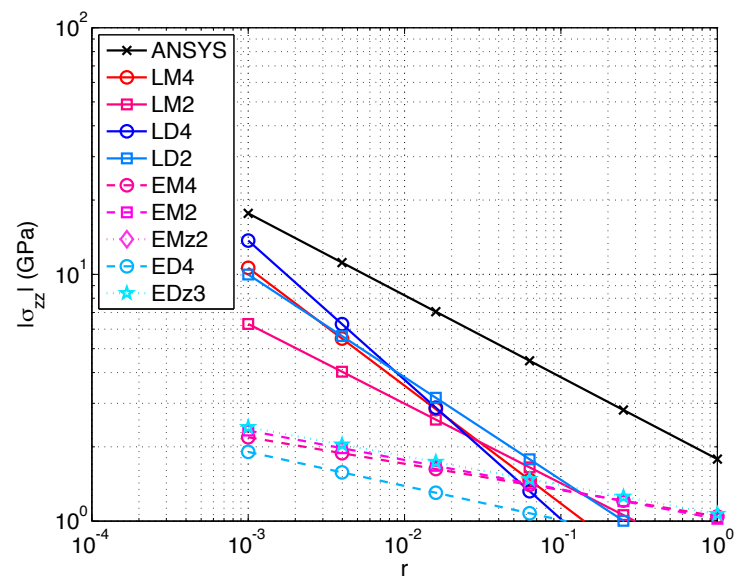

(a) $[0,90]_{s}\left(\epsilon_{0}\right): \sigma_{z z}(x=0, r, z=h / 4)$

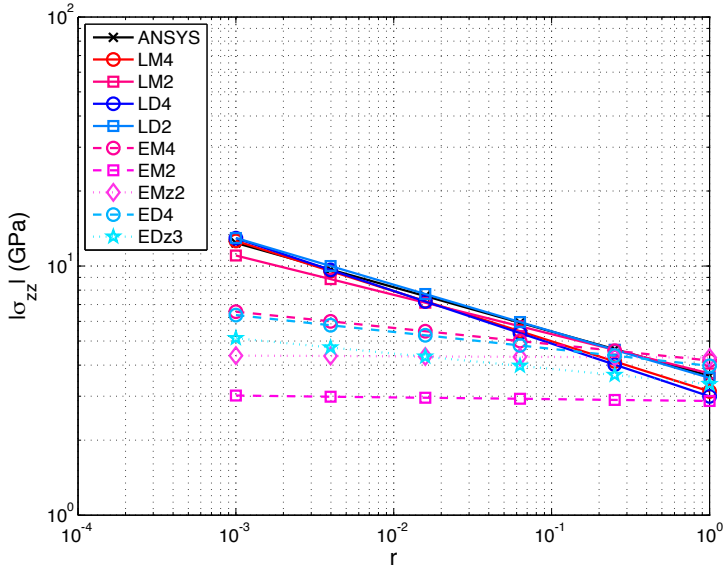

(b) $[0,90]_{s}\left(q_{0}\right): \sigma_{z z}(x=0, r, z=h / 4)$

Figure 14: Transverse normal stress $\sigma_{z z}(r)$ response (log-log scale) for the $[0,90]_{s}$ laminate under extension load (left) and bending load (right): assessment of different CUF models. 


\section{ACCEPTED MANUSCRIPT}

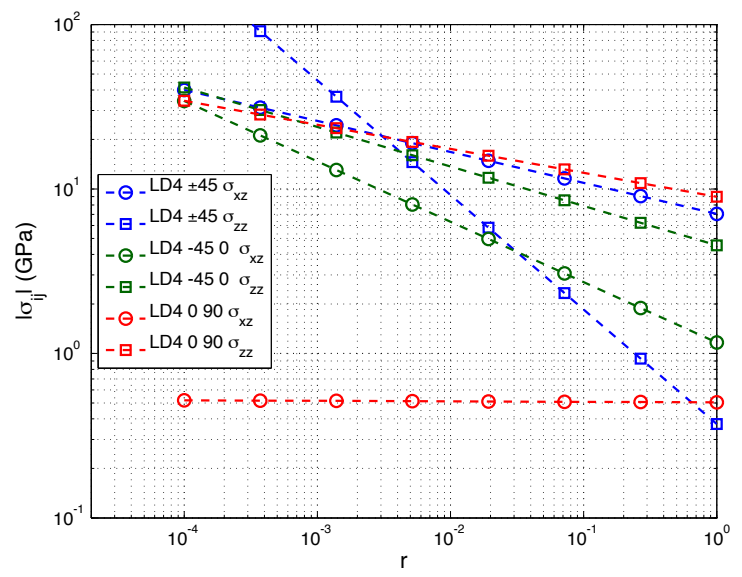

(a) $[ \pm 45,0,90]_{s}\left(\epsilon_{0}\right):\left\{\sigma_{x z}, \sigma_{z z}\right\}(x=0, r, z=h / 4)$

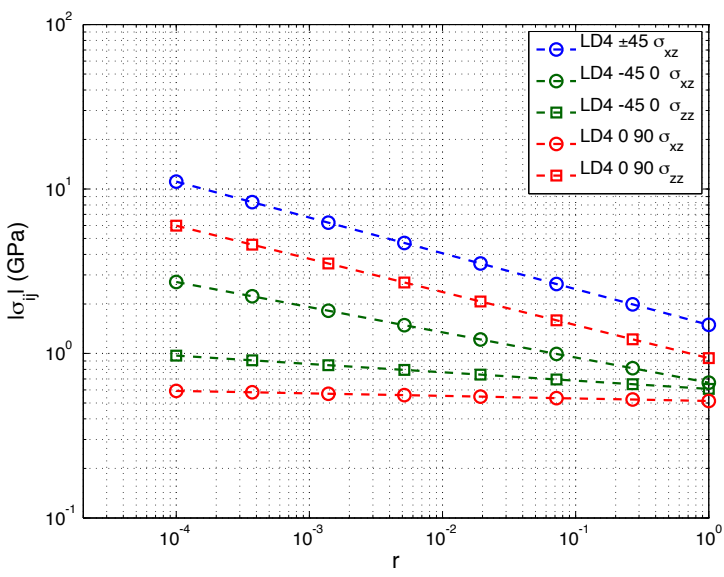

(b) $[ \pm 45,0,90]_{s}\left(q_{0}\right):\left\{\sigma_{x z}, \sigma_{z z}\right\}(x=0, r, z=h / 4)$

Figure 15: Interlaminar stresses at the interfaces of the $[ \pm 45,0,90]_{s}$ laminate under extension load (left) and bending load (right). 


\section{ACCEPTED MANUSCRIPT}

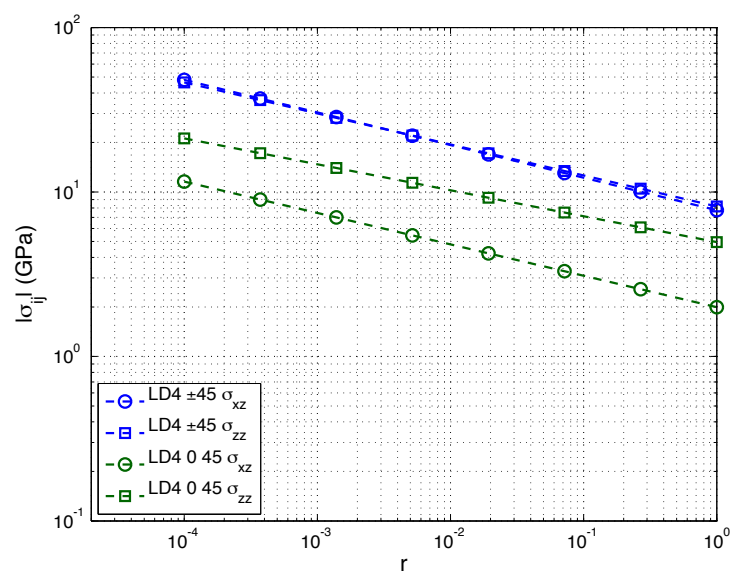

(a) $[90,0, \pm 45]_{s}\left(\epsilon_{0}\right):\left\{\sigma_{x z}, \sigma_{z z}\right\}(x=0, r, z=h / 4)$

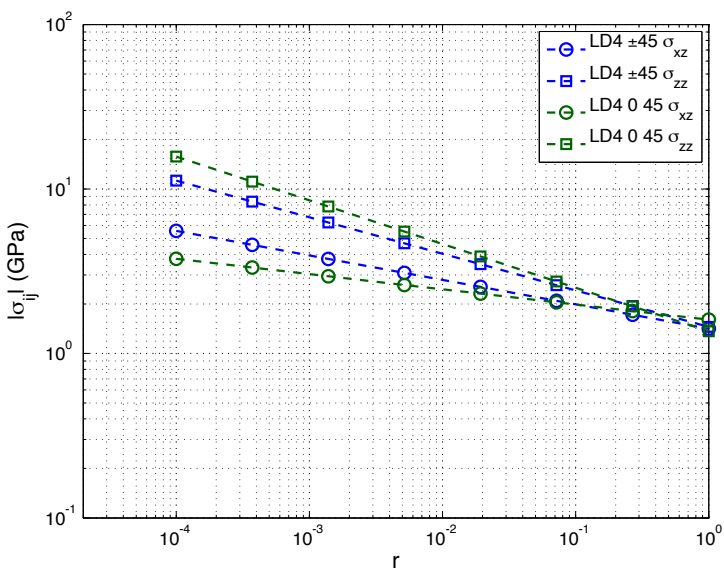

(b) $[90,0, \pm 45]_{s}\left(q_{0}\right):\left\{\sigma_{x z}, \sigma_{z z}\right\}(x=0, r, z=h / 4)$

Figure 16: Interlaminar stresses at the interfaces of the $[90,0, \pm 45]_{s}$ laminate under extension load (left) and bending load (right). 


\section{ACCEPTED MANUSCRIPT}

Table 1: Capabilities and characteristics of the 2D CUF and 3D Ansys models and associated DOFs

\begin{tabular}{c|r|cc|c}
\hline \hline & N=1-4 & ZZ & IC & NDOF \\
\hline \multirow{4}{*}{ PVD } & ED $N$ & - & - & $3(N+1)$ \\
& EDz $N$ & $\sqrt{ }$ & - & $3(N+1)$ \\
& LD $N$ & $\sqrt{ }$ & - & $3\left(N_{l} N+1\right)$ \\
\hline \multirow{3}{*}{ RMVT } & EM $N$ & - & $\sqrt{ }$ & $6+3 N\left(N_{l}+1\right)$ \\
& EMz $N$ & $\sqrt{ }$ & $\sqrt{ }$ & $6+3 N\left(N_{l}+1\right)$ \\
& LM $N$ & $\sqrt{ }$ & $\sqrt{ }$ & $6\left(N_{l} N+1\right)$ \\
\hline & Ansys & $\sqrt{ }$ & - & $3\left(N_{l}\left(2 N_{e z}+1\right)-1\right)$ \\
\hline
\end{tabular}




\section{ACCEPTED MANUSCRIPT}

Table 2: Single ply material properties

\begin{tabular}{c}
\hline \hline$E_{1}=137900 \mathrm{MPa}\left(20.10^{6} \mathrm{psi}\right)$ \\
$E_{2}=E_{3}=14480 \mathrm{MPa}\left(2.110^{6} \mathrm{psi}\right)$ \\
$G_{12}=G_{13}=G_{23}=5860 \mathrm{MPa}\left(0.8510^{6} \mathrm{psi}\right)$ \\
$v_{12}=v_{13}=v_{23}=0.21$ \\
\hline \hline
\end{tabular}




\section{ACCEPTED MANUSCRIPT}

Table 3: Parameters of the employed mesh. Values in parentheses indicate the spacing ratios used to densify the mesh towards the free-edge ( $x$ and $y$ direction) and ply interfaces ( $z$ direction).

\begin{tabular}{llrl}
\hline \hline & & Extension & Bending \\
\hline Mesh I & $N_{e x}$ & $32(64)$ & $32(64)$ \\
& $N_{e y}$ & $32(32)$ & $32(32)$ \\
(for Ansys) & $N_{e z}$ & $8(12)$ & $12(12)$ \\
Mesh II & $N_{e x}$ & $8(20)$ & $24(20)$ \\
& $N_{e y}^{i n}$ & $30(60)$ & $20(60)$ \\
& $N_{e y}^{b r}$ & $30(20)$ & $30(20)$ \\
(for Ansys) & $N_{e z}$ & $8(12)$ & $12(12)$ \\
\hline \hline
\end{tabular}




\section{ACCEPTED MANUSCRIPT}

Table 4: Pressure load magnitude $q_{0}$ for the different laminates

\begin{tabular}{lr}
\hline \hline laminate & $q_{0}[\mathrm{MPa}]$ \\
\hline$[ \pm 45]_{s}$ & 5130.060 \\
{$[0,90]_{s}$} & 253.453 \\
{$[ \pm 45,0,90]_{s}$} & 298.798 \\
{$[90,0, \pm 45]_{s}$} & 213.531 \\
\hline
\end{tabular}

